\title{
A Pilot Study on the Sound Absorption Characteristics of Chicken Feathers as an Alternative Sustainable Acoustical Material
}

\author{
Asniawaty Kusno ${ }^{1}{ }^{\oplus}$, Kimihiro Sakagami ${ }^{2, *}$, Takeshi Okuzono ${ }^{2}$, Masahiro Toyoda ${ }^{3}$, \\ Toru Otsuru ${ }^{4}$, Rosady Mulyadi ${ }^{1}$ (D) and Kusno Kamil ${ }^{5}$ (D) \\ 1 Department of Architecture, Faculty of Engineering, Hasanuddin University, Gowa 92171, Indonesia; \\ asniawaty@unhas.ac.id (A.K.); rosady@unhas.ac.id (R.M.) \\ 2 Environmental Acoustics Lab., Department of Architecture, Grad. Sch. of Engineering, Kobe University, \\ Rokko, Nada, Kobe 657-8501, Japan; okuzono@port.kobe-u.ac.jp \\ 3 Department of Architecture, Faculty of Environmental and Urban Engineering, Kansai University, \\ Yamate-cho, Suita, Osaka 564-8680, Japan; toyoda@kansai-u.ac.jp \\ 4 Department of Architecture and Mechatronics, Oita University, Dannoharu, Oita 870-1192, Japan; \\ otsuru@oita-u.ac.jp \\ 5 Mechanical Engineering Department, Engineering Faculty, Universitas Muslim Indonesia, Makassar 90231, \\ Indonesia; kusno.kamil@umi.ac.id \\ * Correspondence: saka@kobe-u.ac.jp; Tel.:+81-78-803-6043
}

Received: 1 February 2019; Accepted: 6 March 2019; Published: 11 March 2019

\begin{abstract}
This communication reports the results of a pilot study on the sound absorption characteristics of chicken feathers (CFs). Recently, demands for natural and sustainable materials have been extensively studied for acoustical purposes. CF has long been left wasted, however, they can be used for sound-absorbing purposes to improve acoustical environments as a sustainable and green acoustical material. In order to clarify their feasibility, samples of $C F$ absorbers of various densities and thicknesses were prepared, and their sound absorption coefficients were measured by the standard impedance tube method. The measured results were also compared with those of conventional glass wools of the same densities and thicknesses. The results show that CFs have potentially good sound-absorption performance, which is similar to typical fibrous materials: increasing with frequency. Results of direct comparison with glass wool demonstrate that the absorption coefficients of CFs are comparable and, at some frequencies, somewhat higher than conventional glass wools in some cases. Additionally, the first step for searching a prediction method for the sound absorption performance of CFs, their flow resistivity was measured and a Delany-Bazley-Miki model was examined. However, the resultant flow resistivity was unexpectedly low, and the model gave only a much lower value than that measured. The reason for the discrepancies is the subject of a future study.
\end{abstract}

Keywords: chicken feather; sound absorption; sustainable material; flow resistivity

\section{Introduction}

Sound-absorption materials are very important to control the sound environment, both in a building and outdoor built environment. They are used to absorb sound energy in a room to reduce noise levels, as well as to control the reverberation time. These are necessary not only to improve the sound environment in a room, but also necessary to maintain good conditions for speech communication, which can be of vital importance in emergency cases [1]. In outdoor spaces, they are used for suppressing sound reflection which in many cases causes noise problems around heavy 
traffic etc. [2]. Therefore, producing a quality sound-absorbing material is of paramount interest in both building acoustics and noise control.

For these purposes, fibrous and porous materials, such as mineral wools, e.g., glass wool, rock wool, etc., or plastic foams such as urethane foams, etc., have traditionally been used. However, with increasing demand for environmentally-friendly materials, the next-generation sound absorbing materials, such as microperforated panels (MPPs), membrane materials, recycled and other new type fibrous/porous materials, etc. have been extensively studied [3-5], and some of them have recently become commercially available. Furthermore, various natural materials have been studied in the last decade [6,7]. Many results for sound-absorbing materials made of natural materials from natural fibers, for example, coir [8], kenaf [9,10], bamboo [11], wool, etc. have been published [12]. The methodology for acoustic characterization of natural fibers are also studied [13].

Among many alternatives, the authors focus on chicken feather (CF). CFs are a well-known by-product of making poultry products in many countries, and have been left wasted except for limited use such as pillow fillers, feather dusters, handicrafts, etc. As it is also a natural fiber, CF can be one of the potential alternatives for sustainable acoustical material and it is worth studying its acoustical properties. There are of course many factors to consider before CFs are actually used for acoustical purposes, e.g., manufacturing cost, operational lifespan, performance in severe humidity or climates, fire resistivity, thermal properties and other issues. However, it is necessary to clarify the acoustical properties, especially the sound-absorption performance, of CFs. By this one can confirm whether or not it is suitable for acoustical purposes, particularly as a sound-absorbing material.

The studies on CFs as materials for non-acoustical purposes, e.g., keratin extraction, producing biopolymer or various composites, biomedical purposes, etc., have been reported so far [14-20], but there is rather quite a few studies on its acoustical properties to the authors' best knowledge so far [21]. $\mathrm{CF}$ can be regarded as a kind of fibrous material, however, there is no existing theory or model for the prediction of its acoustical properties. Therefore, it is necessary to carry out an experimental study to measure the sound-absorption coefficient of CFs as a pilot study.

In the field of noise control and architectural acoustics, there are some reports on alternative sustainable acoustic materials and structures as possible substitutions for common fiberglass [21-25]. Therefore, it is useful to compare the measured results for CFs with those for fiberglass.

Also it is important to confirm consistency in measured results, for non-standardized industrial products such as chicken feathers. In that case, the measured results should be statistically confirmed through standard deviations. Also, as a basic physical parameter characterizing the acoustical materials, it is necessary to measure flow resistivity.

Hence, this study first presents the detailed explanation of preparation of CF samples for experiments. Next, the normal incidence absorption coefficients of those samples are measured by the standard transfer function method in an acoustic tube. The measured absorption coefficients are compared with those of common fiberglass wools. Also the standard deviations of the measured results are discussed for confirming the consistency of the measured results. Finally, the flow resistivity values of the CF samples are measured by the standard direct flow method, and discuss the possibility of the applicability of the Delany-Bazley-Miki model [26-29], which has been widely used for fibrous materials.

\section{Experiments}

\subsection{Materials and Preparation of the Test Specimens}

For the experimental study, only clean and soft feathers from healthy chicken were used. For this reason, feathers from chicken's wings and tail were excluded. The preparation process of CFs is: First, CFs were thoroughly washed by liquid soap and rinsed. Secondly, the washed CFs were soaked in bleach and disinfectant solutions for a whole night. Then, they were exposed to direct sunlight for two days. These processes are shown in Figure 1. 
The cleaning process was aimed to expel pathogenic microorganism, bacteria, fungi and virus, and this is also important because it will ensure the durability and effective lifetime of the dried feathers. Sixty pieces of CF specimen were made by compacting CF inside cylindrical containers made of mesh of natural material thread. The containers were of 25, 50, and $75 \mathrm{~mm}$ thickness and diameter adjusted to fit into the impedance tube of $100 \mathrm{~mm}$ diameter. Note that in this preparation binder was not used, but just CFs put in the mesh container so that the density of the sample became the designated values below. Also, the samples were not pressed in a compaction process. In this configuration, the compacted samples were prepared to be of the densities 48 and $60 \mathrm{~kg} / \mathrm{m}^{3}$ for each thickness $(25,50$ and $75 \mathrm{~mm})$, as shown in Figure 2. Hereafter, the specimens are indicated according to the thickness and density of the group, i.e., $\mathrm{CF}$ (thickness).(density); e.g., CF50.48, which means CF sample of $48 \mathrm{~kg} / \mathrm{m}^{3}$ density and $50 \mathrm{~mm}$ thickness. For each group, 10 samples were prepared.

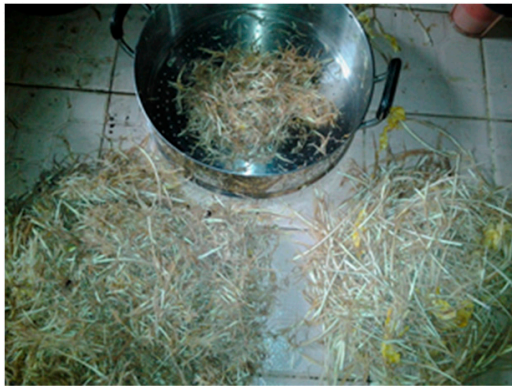

(a)

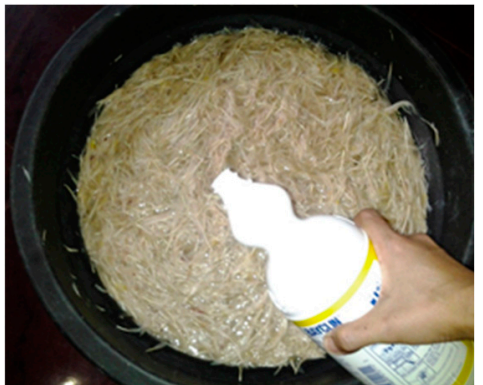

(b)

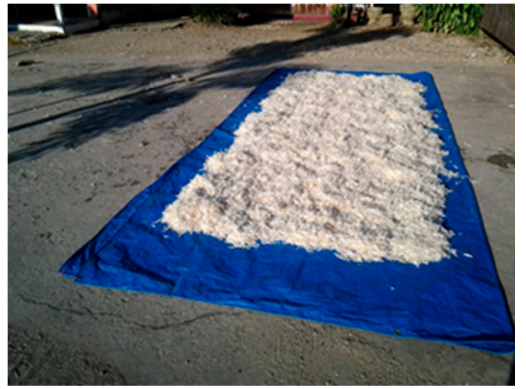

(c)

Figure 1. Cleaning process: (a) chicken feather separation process, (b) washing and soaking with soap and disinfectant solution, and (c) drying under direct sunlight.

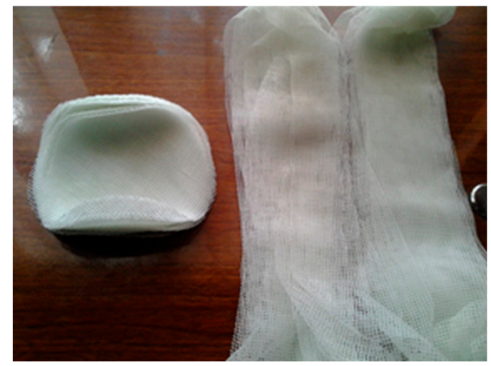

(a)

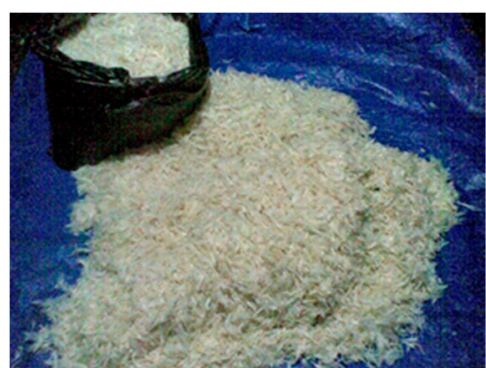

(d)

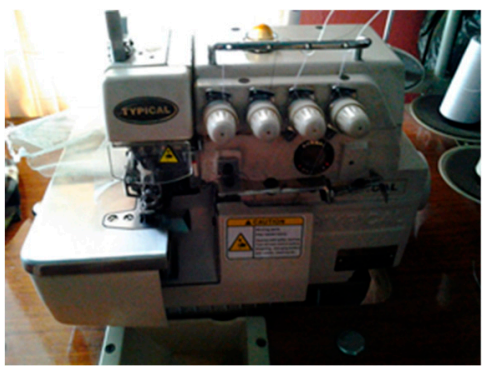

(b)

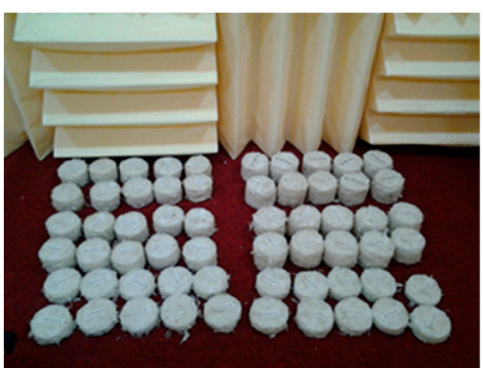

(e)

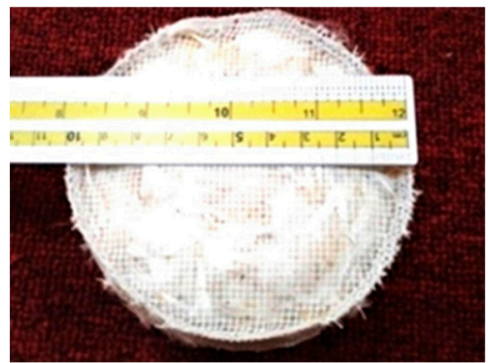

(c)

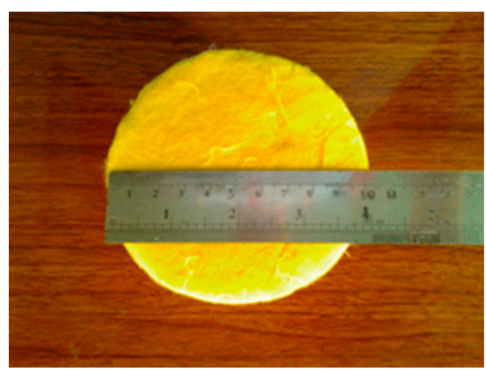

(f)

Figure 2. Specimen preparation process: (a) plastic mesh; (b) mesh sewing machine; (c) mesh-compacted CF; (d) clean and dry raw CF; (e) CFs of various thicknesses and densities; (f) standard industrial glass wool (GW). 


\subsection{Experimental Method}

In the experiments, the normal incidence sound absorption coefficients of CF samples prepared by the procedure mentioned above are measured in an impedance tube. A conventional two-microphone impedance tube (B\&K 4206) is used for the measurement according to ISO 10534-2 as shown in Figure 3. For each group of samples, eight measured data were taken and statistically analyzed later.

The tube of $100 \mathrm{~mm}$ diameter was used in the measurement. The center of the pair microphones (separation $5 \mathrm{~cm}$ ) is at $12.5 \mathrm{~cm}$ from the specimen surface. The analysis of the measured sound absorption coefficients is carried out with grouping the data based on the thickness and density of specimen. In this study, the frequencies from $100 \mathrm{~Hz}$ to $1.6 \mathrm{kHz}$, which is below the cut-off frequency of the $100 \mathrm{~mm}$ tube used, is considered in the following analyses and comparisons. Also, considering that $250 \mathrm{~Hz}-2 \mathrm{kHz}$ is the most important for speech communication [30], the measurement in $100 \mathrm{~Hz}-1.6 \mathrm{kHz}$ gives suitable evaluation of the feasibility of CFs as a sound absorption material, particularly to improve the sound environment in a room in built environments.

The measured results are also statistically analyzed to examine their standard deviation in each sample category. For the reference, the normal incidence sound-absorption coefficients of glass wools (GWs) of the same densities and thicknesses are measured and compared with the measured results of $\mathrm{CFs}$ of corresponding density and thickness. In the measurements, all specimens are installed at the end of the impedance tube, and directly backed by a rigid end.

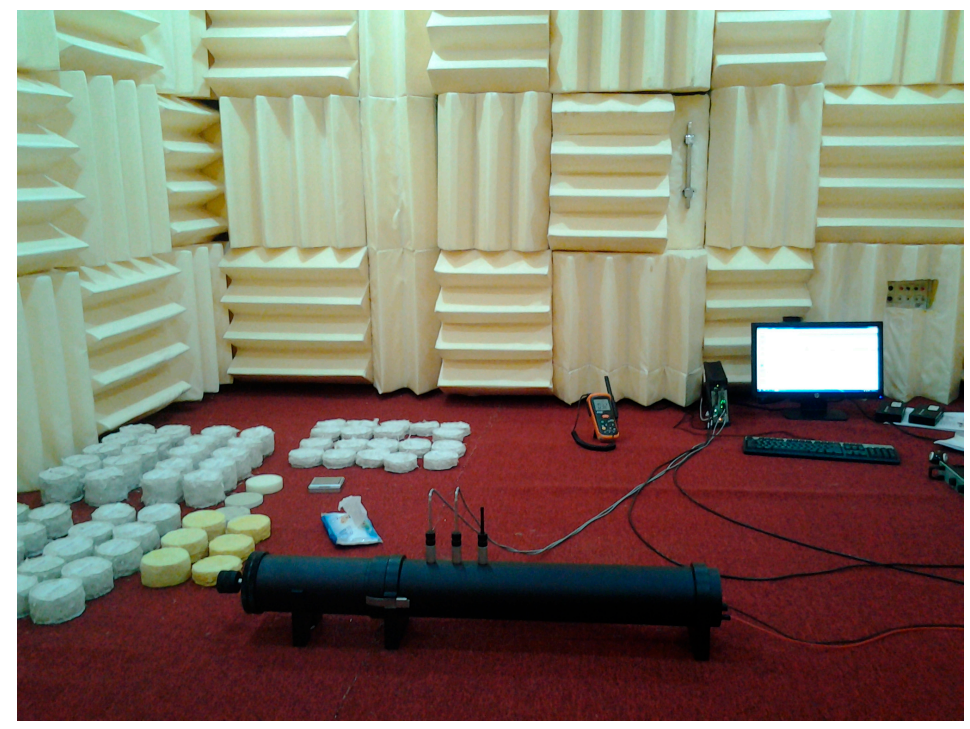

Figure 3. Measurement set-up: an impedance tube is placed in an anechoic room. The center of the pair microphone (separation: $5 \mathrm{~cm}$ ) is located at $12.5 \mathrm{~cm}$ from the specimen surface.

\section{Results and Discussion}

\subsection{Absorption Coefficients of Chicken Feathers}

As mentioned in the previous section, the normal sound absorption coefficients of the prepared CF samples of $48 \mathrm{~kg} / \mathrm{m}^{3}$ and $60 \mathrm{~kg} / \mathrm{m}^{3}$ (for the both densities, $25 \mathrm{~mm}, 50 \mathrm{~mm}$ and $75 \mathrm{~mm}$ thick samples are prepared) were measured in the impedance tube.

Figures 4 and 5, respectively, show the measured results of CF of various densities and thicknesses. The curves indicate the mean values of all samples of the same density and thickness (indicated as CF25.48 etc.), maximum values (maxCF25.48 etc.) and minimum values (minCF25.48 etc.). In all graphs the standard deviation of the samples of the same density and thickness is also indicated by the curves in black for reference. 


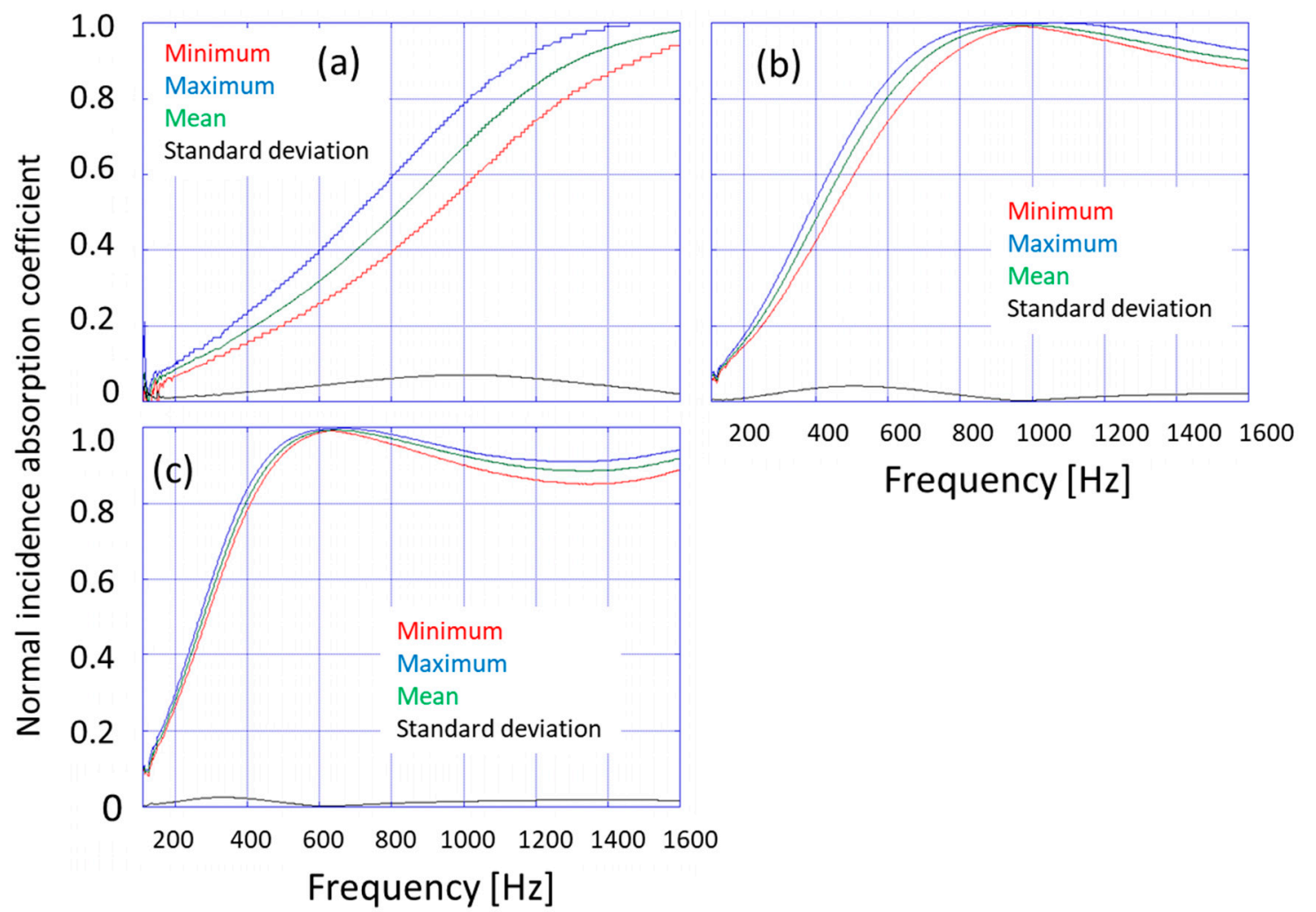

Figure 4. Mean (green curves), minimum (red curves) and maximum (blue curves) of the measured absorption coefficients for chicken feathers with a density of $48 \mathrm{~kg} / \mathrm{m}^{3}$, (a) $25 \mathrm{~mm}$ (CF25.48), (b) $50 \mathrm{~mm}$ (CF50.48), and (c) $75 \mathrm{~mm}$ (CF75.48). Standard deviation of each specimen group is indicated by black curves.

As is observed, all samples show the absorption coefficient increasing with the frequency, which is typical for porous/fibrous materials [29,30]: namely the sound absorption is considered to be caused by thermal and viscous losses in pores between fibers of feathers. Therefore, CF can be regarded as an alternative for porous/fibrous materials. Although the deviation of the absorption coefficient becomes rather large when CF is light $\left(48 \mathrm{~kg} / \mathrm{m}^{3}\right)$ and thin $(25 \mathrm{~mm})$, on the whole the absorption characteristics become higher at low frequencies when it becomes thicker. Also, heavier CF $\left(60 \mathrm{~kg} / \mathrm{m}^{3}\right)$ gives higher absorption coefficients than lightweight ones $\left(48 \mathrm{~kg} / \mathrm{m}^{3}\right)$. These are similar to other porous/fibrous absorbers, and may suggest that the sound-absorbing mechanism of CF is basically similar to those absorbers.

As for consistency of the measured results, although the standard deviation of CF25.48 is rather larger (0.07 at the maximum), in other cases it is rather lower. In particular, in the case of the CFs of $60 \mathrm{~kg} / \mathrm{m}^{3}$, the standard deviation becomes lower than that for $48 \mathrm{~kg} / \mathrm{m}^{3}$ cases. Considering the above results, the basic behavior of the sound absorption of CFs is similar. Also, comparing the standard deviation indicated in Figures 4 and 5, the tendency that heavier and thicker samples show smaller standard deviation. Therefore, the acoustical properties of CFs are relatively more stable when the material is thick and of large density. From observation of the samples, this can be interpreted to be related to the organization of the sample: the feathers are more crammed in the container in the thick and larger density samples, which can make them more homogeneous.

For reference, an example of the measured normal incidence absorption characteristics of GW of $48 \mathrm{~kg} / \mathrm{m}^{3}$ and 25, 50, $75 \mathrm{~mm}$ (GW25.48, GW50.48, and GW75.48, respectively) thick are shown in Figure 6 in comparison with CFs of the same densities and thicknesses. Comparing CF of $50 \mathrm{~mm}$ and GW50.48, CF shows comparable (in the case of CF50.48) or better (CF50.60) performance, for example. Therefore, it may be stated that $\mathrm{CF}$ s has a potential possibility as an alternative sustainable sound-absorbing material. 


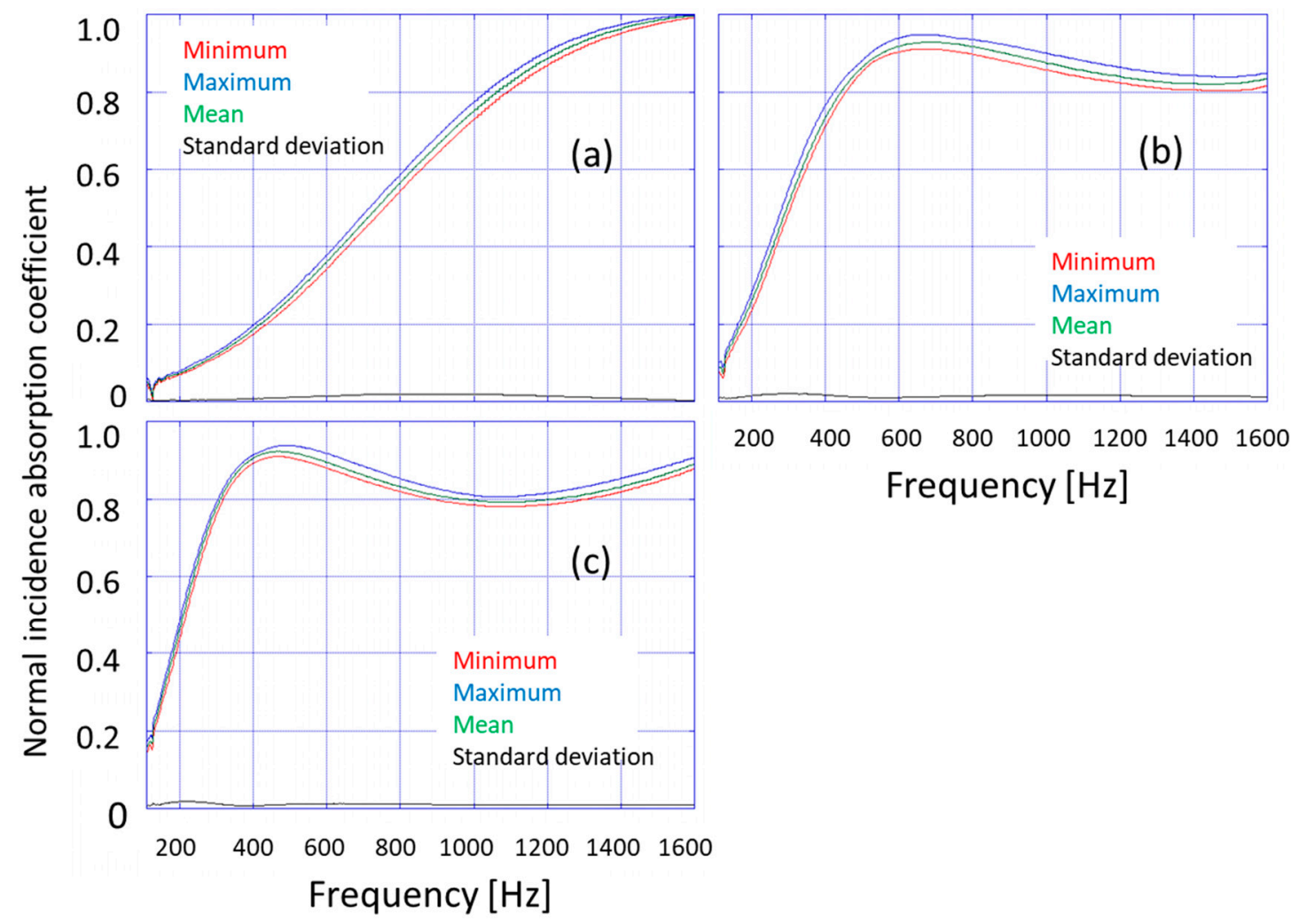

Figure 5. Mean (green curves), minimum (red curves) and maximum (blue curves) of the measured absorption coefficients for chicken feathers with density of $60 \mathrm{~kg} / \mathrm{m}^{3}$, (a) $25 \mathrm{~mm}$ (CF25.60), (b) $50 \mathrm{~mm}$ (CF50.60), and (c) $75 \mathrm{~mm}$ (CF75.60). Standard deviation of each specimen group is indicated by black curves.

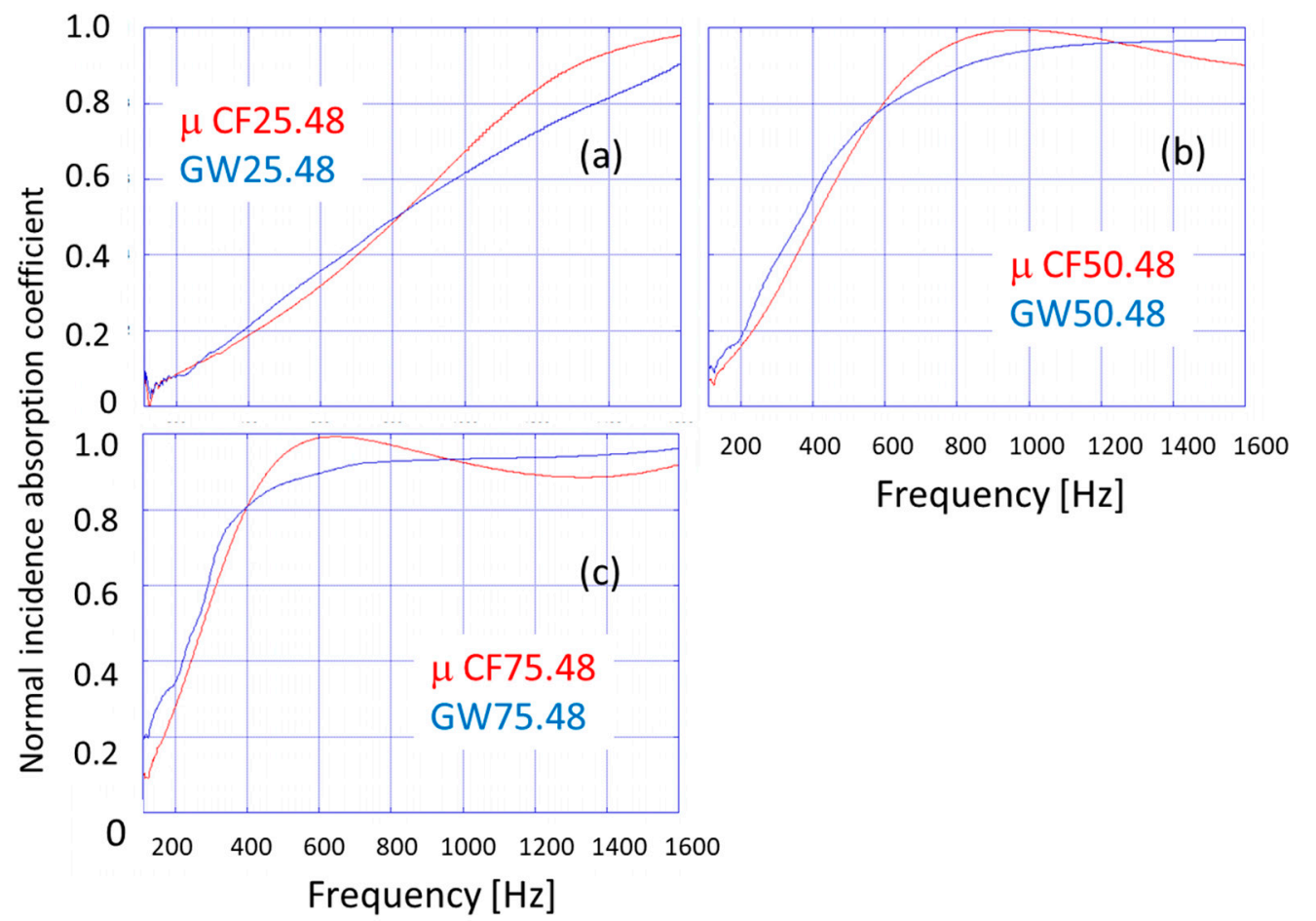

Figure 6. Comparison of the measured absorption coefficients of glass wool (density $48 \mathrm{~kg} / \mathrm{m}^{3}$. Blue curves) with CFs (density $48 \mathrm{~kg} / \mathrm{m}^{3}$. Mean values. Red curves.). Thickness: (a) 25, (b) 50 and (c) $75 \mathrm{~mm}$. 


\subsection{Flow Resistivity of Chicken Feather}

Flow resistivity is one of the most important factors of porous/fibrous materials to characterize its sound absorption properties. Therefore, the flow resistivity of CFs was measured by the conventional direct current method. The measurement was carried out with refer to ISO 9053, but due to the limitation of the compressor to generate direct air flow and the sensor, the lowest flow velocity in the measurement was $0.005 \mathrm{~m} / \mathrm{s}$. Therefore, we had to employ the extrapolation method based on JIS A 6306 (now abolished): Measurement of the differential pressures were made at various flow speeds. After having checked the linearity of the resultant differential pressures, the extrapolated value of differential pressure for the flow velocity of $0.0005 \mathrm{~m} / \mathrm{s}$ was obtained.

For the restriction of the measurement apparatus, the same samples used in the impedance tube measurement described above could not be used, because the equipment used to measure flow resistivity was made of a square tube. Measurement set up is shown in Figure 7. Therefore, CF samples of the same densities and thickness were newly prepared. The samples were square with sides of $100 \mathrm{~mm}$. Only one difference was that the shape of the container which contains chicken feathers is not cylindrical but square box-like shape. In order to avoid air leakage, clay was used to close the possible gap between the sample and the testing tube. The measurement was very carefully made at least three times for one sample, and five samples from a group, so that the deviation could be minimized. The same measurement was repeated on the other day to avoid the influence of weather.

The results are shown in Table 1. Considering the sound absorption coefficients shown in Figures 4 and 5, one can find that flow resistivity is unexpectedly low. As is widely known, the flow resistivity of GWs is usually much larger (typically around $14000 \mathrm{~Pa} \mathrm{~s} / \mathrm{m}^{2}$ ) $[12,29,30]$. The reason of this low flow resistivity is not exactly known in the current stage, however, it may be inferred that the fiber of CFs is rather thick and heavy compared to other fibrous materials resulting from fewer fibers in a sample than other fibrous materials, Also, it may be relevant that the sample is rather sparse compared to other conventional fibrous materials.

As a trial, the Delany-Bazley-Miki (DBM) model [26-29] was employed to examined its applicability to CFs. This model is often used for fibrous materials to predict the characteristic impedance and propagation constant from the flow resistivity only. Using this model, the characteristic impedance $Z$ and propagation constant of material are given by the following equations, with the flow resistivity $R\left(\mathrm{~Pa} \mathrm{~s} / \mathrm{m}^{2}\right)$ of the material and the frequency $f(\mathrm{~Hz})$ as follows:

$$
\begin{gathered}
Z=\left\{1+0.07\left(\frac{f}{R}\right)^{-0.632}+i 0.107\left(\frac{f}{R}\right)^{-0.632}\right\} \rho_{0} c_{0} \\
\gamma=k_{0}\left\{0.160\left(\frac{f}{R}\right)^{-0.618}\right\}-i k_{0}\left\{1+0.109\left(\frac{f}{R}\right)^{-0.618}\right\}
\end{gathered}
$$

where $\rho_{0}$ is the air density and $k_{0}=\omega / c_{0}$ with $\omega$ the angular frequency and $c_{0}$ the sound speed in air.

Once $Z$ and $\gamma$ are obtained from Equations (1) and (2), the surface impedance of a material with rigid backing is given by the well-known formula, from which its normal incidence absorption coefficient is easily derived [29,30].

An example of the prediction results of sound absorption coefficient of CF50.48 (50 mm thick and density $48 \mathrm{~kg} / \mathrm{m}^{3}$ ) using the measured flow resistivity is shown in Figure 8, in comparison with the predicted value of GW50.48 by the same method. In these examples, the average of the measured flow resistivity for $\mathrm{CF}$ of $48 \mathrm{~kg} / \mathrm{m}^{3}$, i.e., $814 \mathrm{~Pa} \mathrm{~s} / \mathrm{m}^{2}$ is used, and for GW50.48 the flow resistivity is assumed to be $14,000 \mathrm{~Pa} \mathrm{~s} / \mathrm{m}^{2}$, which is typical for glass wool. 
The predicted value for GW can be considered as reasonable if it is compared with Figure $6 \mathrm{~b}$, whereas that for CF is obviously lower than the measured value in Figure $4 \mathrm{~b}$. This suggests that the Delany-Bazley-Miki model cannot give an appropriate prediction for CFs. The measured absorption coefficient of CF50.48 is comparable with or, at some frequencies, higher than GW50.48.

As the Delany-Bazley-Miki model is originally derived from measured results of fibrous materials and uses only the flow resistivity of the material, it is interpreted that if the sound absorption coefficient of a material is comparable to glass wool, the flow resistivity of the material should be also comparable to the glass wool. However, the sound absorption coefficient of CF is comparable with glass wool, but its flow resistivity is much lower than glass wool. Therefore, it is concluded that the sound absorption by CFs may not be characterized by flow resistivity only: i.e., it requires a more sophisticated model using other parameters. However, the reason of this discrepancy is not known in the current stage, and is a subject of future studies. Also, it is necessary to try another model, or if needed, to try to establish a new model applicable to CFs.

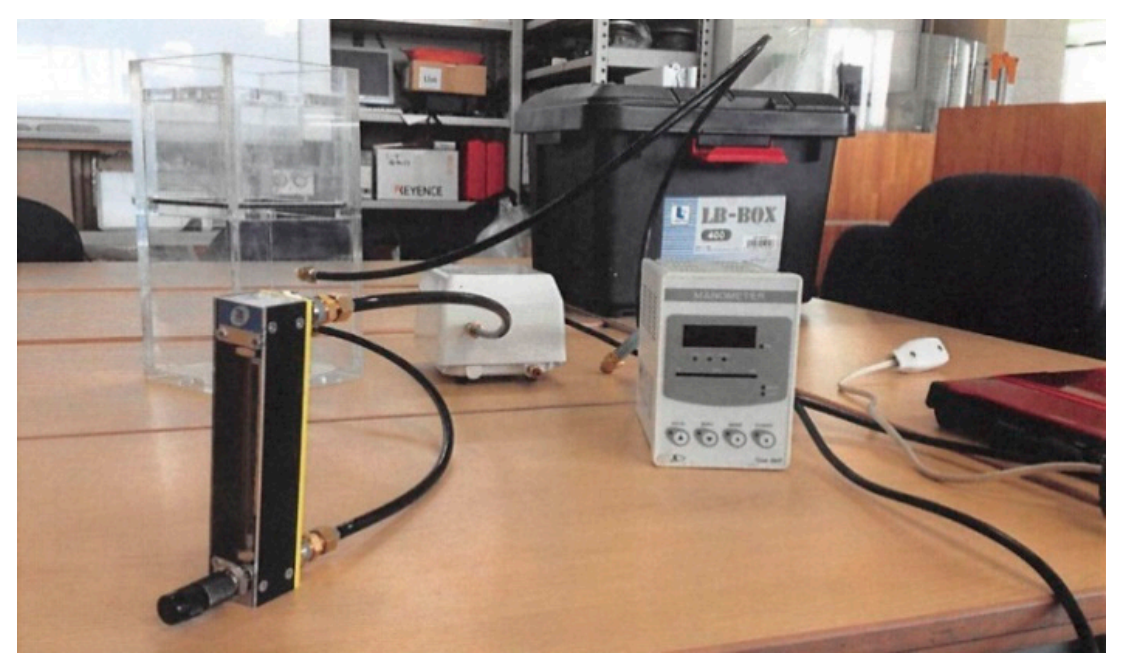

Figure 7. Set up for flow resistivity measurement. The specimens are installed in the transparent square tube on the left. Direct steady air flow is caused in the tube by a compressor which is controlled by flow velocity meter. Differential pressure between both sides of the specimen is measured by a digital manometer.

Table 1. Measured flow resistivity of chicken feathers.

\begin{tabular}{ccccc}
\hline Density $\mathbf{4 8} \mathbf{~ k g} / \mathbf{m}^{\mathbf{3}}$ & $\mathbf{2 5} \mathbf{~ \mathbf { m }}$ & $\mathbf{5 0} \mathbf{~} \mathbf{m}$ & $\mathbf{7 5} \mathbf{~ \mathbf { m }}$ & \\
\hline Specimen 1 & 1004 & 1109 & 439 & \\
Specimen 2 & 797 & 752 & 740 & \\
Specimen 3 & 440 & 1512 & 536 & Total Avg. \\
Average & 747 & 1124 & 572 & $814\left(\mathrm{~Pa} \mathrm{~s} / \mathbf{m}^{2}\right)$ \\
\hline Density $\mathbf{6 0} \mathbf{~ k g / \mathbf { m } ^ { \mathbf { 3 } }}$ & $\mathbf{2 5} \mathbf{~ \mathbf { m }}$ & $\mathbf{5 0} \mathbf{~ \mathbf { m }}$ & $\mathbf{7 5} \mathbf{~ \mathbf { m }}$ & \\
\hline Specimen 1 & 1444 & 986 & 1100 & \\
Specimen 2 & 524 & $\mathbf{6 6 6}$ & 1339 & \\
Specimen 3 & 891 & 817 & 1154 & Total Avg. \\
Average & 953 & 823 & 1198 & $991\left(\mathrm{~Pa} \mathrm{~s} / \mathbf{m}^{2}\right)$ \\
\hline
\end{tabular}




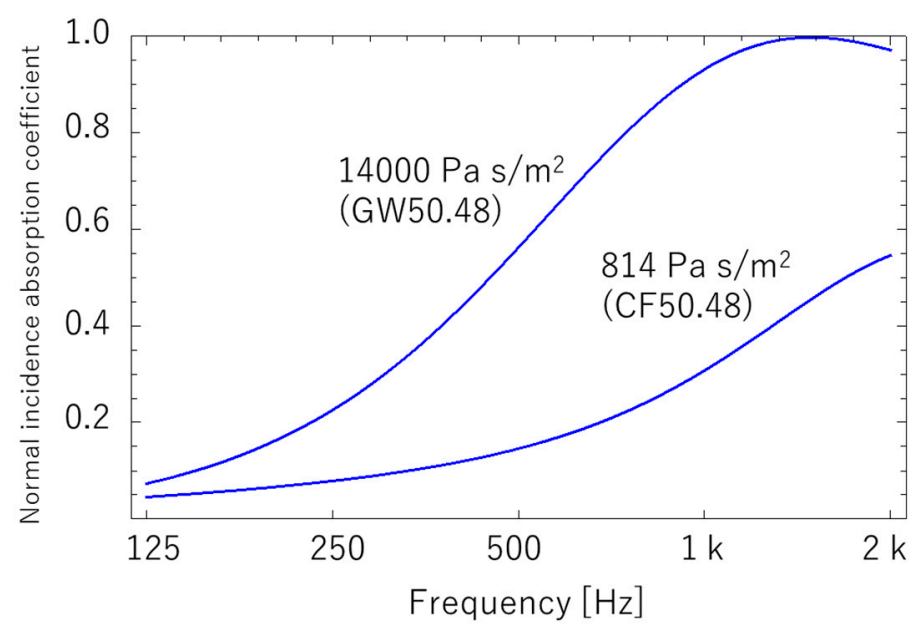

Figure 8. Normal absorption coefficient of CF (CF50.48) in comparison with GW (GW50.48) as predicted by the Delany-Bazley-Miki model. Thickness $50 \mathrm{~mm}$, density $48 \mathrm{~kg} / \mathrm{m}^{3}$. The calculation for CF50.48 is made with the measured flow resistivity is $814 \mathrm{~Pa} \mathrm{~s} / \mathrm{m}^{2}$ from Table 1 . The flow resistivity for GW50.48 is estimated as $14000 \mathrm{~Pa} \mathrm{~s} / \mathrm{m}^{2}$, which is typical value for glass wools.

\section{Concluding Remarks}

In this communication, the results of a pilot study of the absorption characteristics of chicken feathers (CFs) are reported. The study is aimed at producing an alternative sustainable and environmentally friendly sound absorption material using wasted chicken feathers.

First, the procedure to prepare the measurement sample of $\mathrm{CF}$ absorbers was presented in detail. Then, the measurement of normal incidence sound absorption coefficient by standard impedance tube method was carried out. The measured results show that CFs demonstrate comparable, or in some cases better, sound-absorption performance than glass wool.

Also, measurement of the flow resistivity of CFs was performed. Flow resistivity is one of fundamental parameters to characterize fibrous/porous absorption material, and those of CFs were unexpectedly low despite of their high sound absorptivity. With the measured value of flow resistivity, a trial to prediction was made using the Delany-Bazley-Miki model, which uses the flow resistivity of material. However, the model could not give a reasonable prediction for CFs for the cases studied in the present study. It is necessary for some more work to be done to improve the performance of CFs as well as to establish a model for prediction in future works.

Future work should also include examination of fire resistivity, thermal properties, durability and other considerations, which are important in actual situations.

Author Contributions: Project administration, experiments, data analysis and writing-original draft preparation: A.K.; supervision, writing-review and editing, data analysis and theoretical analysis: K.S. and T.O. (Takeshi Okuzono); flow resistivity measurement and analysis: M.T.; methodology advisor: T.O. (Toru Otsuru); assistance in experiments: R.M.; supervision in measurements: K.K.

Funding: This work was in part supported by Hasanuddin University through research grant within the scheme of BMIS-2016/2017.

Acknowledgments: The authors are indebted to Siti Haisah and Vovianty Masgode for their assistance in this experimental work.

Conflicts of Interest: The authors declare no conflict of interest. 


\section{References}

1. Sato, H.; Morimoto, M.; Wada, M. Relationship between listening difficulty rating and objective measures in reverberant and noisy sound fields for young adults and elderly persons. J. Acoust. Soc. Am. 2012, 131, 4596-4605. [CrossRef] [PubMed]

2. Hothersall, D.C.; Horoshenkov, K.V.; Mercy, S.E. Numerical modelling of the sound field near a tall building with balconies near a road. J. Sound Vib. 1996, 198, 507-515. [CrossRef]

3. Fuchs, H.V. Alternative fibreglass absorbers-New tools and materials for noise control and acoustic comfort. Acust. Acta Acust. 2001, 87, 414-422.

4. Arenas, J.P.; Crocker, M.J. Recent trend in porous sound-absorbing materials. Sound Vib. 2010, 44, $12-17$.

5. Herrin, D.; Liu, J.; Seybert, A. Properties and applications of microperforated panels. Sound Vib. 2011, 45, 6-9.

6. Asdrubali, F. Green and sustainable materials for noise control in buildings. In Proceedings of the 19th International Congress on Acoustics, Madrid, Spain, 2-7 September 2007.

7. Asdrubali, F. Survey on the acoustical properties of new sustainable materials for noise control. In Proceedings of the Euronoise 2016, Tampere, Finland, 30 May-1 June 2006; pp. 1-10.

8. Fouladi, M.H.; Ayub, M.; Nor, M.J.M. Analysis of coir fiber acoustical characteristics. Appl. Acoust. 2011, 72, 35-42. [CrossRef]

9. Lima, Z.Y.; Putra, A.; Nora, M.J.M.; Yaakob, M.Y. Sound absorption performance of natural kenaf fibres. Appl. Acoust. 2018, 118, 107-114. [CrossRef]

10. Chin, D.D.V.S.; Yahya, M.N.B.; Din, N.B.C.; Ong, P. Acoustic properties of biodegradable composite micro-perforated panel (BC-MPP) made from kenaf fibre and polyactic acid (PLA). Appl. Acoust. 2018, 138, 179-187. [CrossRef]

11. Koizumi, T.; Tsujiuchi, N.; Adachi, A. The development of sound absorbing materials using natural bamboo fibers. High performance structures and composites. WIT Trans. Built Environ. 2002, 59, 157-166.

12. Adams, T. Sound Materials: A Compendium of Sound Absorbing Materials for Architecture and Design; Frame Publishers: New York, NY, USA, 2017.

13. Berardi, U.; Iannace, G. Acoustic characterization of natural fibers for sound absorption applications. Build. Environ. 2015, 94, 84-852. [CrossRef]

14. Wang, Y.X.; Cao, X.J. Extracting keratin from chicken feathers by using a hydrophobic ionic liquid. Process Biochem. 2012, 47, 896-899. [CrossRef]

15. Jimenez-Cervantes Amieva, E.; Fuentes-Ramirez, R.; Martinez-Hernandez, A.L.; Millan-Chiu, B.; Lopez-Marin, L.M.; Castaño, V.M.; Velasco-Santos, C. Graphene oxide and reduced graphene oxide modification with polypeptide chains from chicken feather keratin. J. Alloys Compd. 2015, 643, 137-148. [CrossRef]

16. Wang, Q.; Cao, Q.; Wang, X.; Jing, B.; Kuang, H.; Zhou, L. A high-capacity carbon prepared from renewable chicken feather biopolymer for supercapacitors. J. Power Sour. 2013, 225, 101-107. [CrossRef]

17. Reddy, N.; Jiang, Q.; Jin, E.; Shi, Z.; Hou, X.; Yang, Y. Bio-thermoplastics from grafted chicken feathers for potential biomedical applications. Colloids Surf. B Biointerfaces 2013, 110, 51-58. [CrossRef] [PubMed]

18. Reddy, N.; Hu, C.; Yan, K.; Yang, Y. Thermoplastic films from cyanoethylated chicken feathers. Mater. Sci. Eng. C 2011, 31, 1706-1710. [CrossRef]

19. Forgács, G.; Alinezhad, S.; Mirabdollah, A.; Feuk-Lagerstedt, E.; Horváth, I.S. Biological treatment of chicken feather waste for improved biogas production. J. Environ. Sci. 2011, 23, 1747-1753. [CrossRef]

20. Huda, S.; Yang, Y. Composites from ground chicken quill and polypropylene. Compos. Sci. Technol. 2008, 68, 790-798. [CrossRef]

21. Sun, X.; Liang, W. Cellular structure control and sound absorption of polyolefin microlayer sheets. Compos. Part B Eng. 2016, 87, 21-26. [CrossRef]

22. Dragonetti, R.; Romano, R. Considerations on the sound absorption of non locally reacting porous layers. Appl. Acoust. 2015, 87, 46-56. [CrossRef]

23. Binici, H.; Aksogan, O.; Demirhan, C. Mechanical, thermal and acoustical characterizations of an insulation composite made of bio-based materials. Sustain. Cities Soc. 2016, 20, 17-26. [CrossRef]

24. Duan, X.H.; Wang, H.Q.; Li, Z.B.; Zhu, L.K.; Chen, R.; Kong, D.Y.; Zhao, Z. Sound absorption of a flexible micro-perforated panel absorber based on PVDF piezoelectric film. Appl. Acoust. 2015, 88, 84-89. [CrossRef] 
25. Mati-Baouche, N.; De Baynast, H.; Lebert, A.; Sun, S.; Lopez-Mingo, C.J.S.; Leclaire, P.; Michaud, P. Mechanical, thermal and acoustical characterizations of an insulating bio-based composite made from sunflower stalks particles and chitosan. Ind. Crops Prod. 2014, 58, 244-250. [CrossRef]

26. Delany, M.; Bazley, E. Acoustical properties of fibrous absorbent materials. Appl. Acoust. 1970, 3, $105-116$. [CrossRef]

27. Miki, Y. Acoustical properties of porous materials-Generalizations of empirical models. J. Acoust. Soc. Jpn. E 1990, 11, 25-28. [CrossRef]

28. Miki, Y. Acoustical properties of porous materials-Modifications of Delany-Bazley models. J. Acoust. Soc. Jpn. E 1990, 11, 19-24. [CrossRef]

29. Allard, J.F.; Atalla, N. Propagation of Sound in Porous Media: Modelling Sound Absorbing Materials, 3rd ed.; Wiley: Hoboken, NJ, USA, 2009.

30. Maekawa, Z.; Rindel, J.H.; Lord, P. Environmental and Architectural Acoustics; Taylor and Francis: Oxford, UK, 2010.

(C) 2019 by the authors. Licensee MDPI, Basel, Switzerland. This article is an open access article distributed under the terms and conditions of the Creative Commons Attribution (CC BY) license (http://creativecommons.org/licenses/by/4.0/). 